\title{
Percepção e representações de Ciência de estudantes bolsistas de iniciação científica júnior
}

\author{
Perception and representations about Scientific of student \\ scholarships of junior scientific initiation
}

Percepción y representaciones de Ciencia de estudiantes becários de iniciación científica junior

Victor Hugo Nedel Oliveira ${ }^{1}$; Daniel Giordani Vasques ${ }^{1}$

\section{RESUMO}

O debate sobre ciência vem ganhando expressividade em múltiplos espaços, como a escola. O principal objetivo da investigação foi analisar as percepções e representações de ciência de bolsistas de iniciação científica júnior. Para tanto, realizou-se investigação descritiva com 9 bolsistas, estudantes do Ensino Fundamental do Colégio de Aplicação da UFRGS. O instrumento de coleta de dados foi um questionário estruturado em 3 partes: caracterização da amostra; afirmações na escala Likert; questões abertas sobre ciência. As informações coletadas foram submetidas à análise de conteúdo. Os resultados evidenciaram que os sujeitos reconhecem a ciência enquanto instituição necessária, depositando confiança em sua ação. As ações e os conteúdos relacionados à ciência, bem como os desejos e expectativas de resultados dos profissionais do campo científico foram constatados. As representações dos sujeitos sobre ciência são apresentadas em categorias: instrumento; conhecimento; pesquisa; amplitude; tipos de saberes. É possível considerar, portanto, que as bagagens trazidas pelos estudantes devem ser utilizadas como referência, possibilitando a exploração de horizontes científicos e pedagógicos.

Palavras-chave: Ciência; Representação; Iniciação Científica Júnior; Escola; Educação.

\begin{abstract}
The debate on science has been gaining expression in multiple spaces, such as the school. The main objective of the investigation was to analyze the perceptions and representations of science of junior scientific initiation fellows. To this end, a descriptive investigation was carried out with 9 scholarship students, students of elementary school at the College of Application at UFRGS. The data collection instrument was a questionnaire structured in 3 parts: sample characterization; statements on the Likert scale; open questions about science. The collected information was submitted to content analysis. The results showed that the subjects recognize science as a necessary institution, placing confidence in their action. The actions and content related to science, as well as the desires and expectations of results of professionals in the scientific field were verified. The representations of subjects about science are presented in categories: instrument; knowledge; search; amplitude; types of knowledge. It is possible to consider, therefore, that the luggage brought by the students must be used as a reference, allowing the exploration of scientific and pedagogical horizons.
\end{abstract}

Keywords: Science; Representation; Junior Scientific Initiation; School; Education.

\section{RESUMEN}

El debate sobre la ciencia ha ido ganando expresión en múltiples espacios, como la escuela. El principal objetivo de la investigación fue analizar las percepciones y representaciones de la ciencia de los jóvenes becarios de iniciación científica. Para ello, se realizó una investigación descriptiva con 9 alumnos becados, alumnos de primaria del Colégio de Aplicación de la UFRGS. El instrumento de recolección de datos fue un cuestionario

\footnotetext{
${ }^{1}$ UFRGS - Universidade Federal do Rio Grande do Sul, Porto Alegre/RS - Brasil.
} 
estructurado en 3 partes: caracterización de la muestra; declaraciones en la escala Likert; preguntas abiertas sobre ciencia. La información recopilada se sometió a análisis de contenido. Los resultados mostraron que los sujetos reconocen a la ciencia como una institución necesaria, depositando confianza en su acción. Se verificaron las acciones y contenidos relacionados con la ciencia, así como los deseos y expectativas de resultados de los profesionales del campo científico. Las representaciones de sujetos sobre ciencia se presentan en categorías: instrumento; conocimiento; buscar; amplitud; tipos de conocimiento. Se puede considerar, por tanto, que el equipaje que traigan los alumnos debe ser utilizado como referencia, permitiendo la exploración de horizontes científicos y pedagógicos.

Palabras clave: Ciencia; Representación; Iniciación Científica Juvenil; Escuela; Educación.

\section{INTRODUÇÃO}

A ciência e seu debate contemporâneo vieram ganhando força nos últimos meses, principalmente com a chegada da pandemia da COVID-19, que escancarou uma importante tensão: o negacionismo científico. Para que se possa aprofundar o debate sobre a ciência e os múltiplos elementos que dela provém e para ela convergem, se faz necessário debruçar os olhares para os estudos sociais da ciência (LATOUR, 2000), que colaboram na tentativa de entender os fazeres, os processos e as associações envolvidas no cotidiano da pesquisa. A partir desse entendimento, verifica-se que os fazeres da ciência não encontram-se separados dos seus interesses e de suas motivações, o que permite assumir que não existe uma ciência pura, isenta ou ingênua, mas sim uma ação híbrida entre ciência e política, a partir das decisões que se tomam, ou não, em relação ao fazer científico.

A escola, nesse sentido, pode ser considerada como um dos espaços privilegiados de popularização da ciência, na medida em que os conhecimentos construídos com os estudantes a partir dos diversos componentes curriculares têm sua origem, em algum grau, nos processos científicos das múltiplas áreas do saber (DEMO, 1995). A noção de que os conhecimentos trabalhados com os estudantes são conhecimentos científicos ou acadêmicos não inviabiliza o papel da escola enquanto espaço produtor de conhecimento, inclusive, e, por isso, reconhecem-se as estratégias de ensino da ciência da escola básica, a partir de atividades vinculadas à iniciação científica, seja como componente curricular ou como projeto pedagógico complementar. O trabalho com o método científico no seio da escola, nessa leitura, possibilita a formação de cidadãos críticos e que estejam atentos às mudanças que ocorrem na sociedade, de modo a que tenham o entendimento de que a ciência constitui-se de importante instituição pra o avanço da sociedade como um todo.

Para que fosse possível desbravar os diferentes cenários da iniciação científica no âmbito escolar, propor ações pedagógicas que fomentem e incentivem as práticas educativas sobre e com a temática e, ao mesmo tempo, reconhecer as investigações que vêm tratando do tema no país, optou-se pela criação de um projeto de pesquisa que vem sendo desenvolvido, institucionalmente, no Colégio de Aplicação da Universidade Federal do Rio Grande do Sul (UFRGS), espaço privilegiado para a pesquisa e a prática do assunto na escola básica. Na instituição em tela, os estudantes possuem contato com a iniciação científica desde o primeiro ano do Ensino Fundamental, passando pelos anos finais dessa etapa de ensino e pelo ensino médio - com a possibilidade de bolsas de IC Júnior, e também na Educação de Jovens e Adultos (EJA), com disciplina relativa à iniciação científica. No ano de 2020, o referido projeto de pesquisa conta com significativo número de bolsistas de IC Júnior, que desenvolvem investigações sobre temas relacionados à ciência, educação e sociedade.

O principal objetivo do presente texto foi analisar as percepções e as representações sobre ciência e sobre iniciação científica na escola de bolsistas de iniciação científica júnior, estudantes do Ensino 
Fundamental do Colégio de Aplicação da UFRGS, vinculados ao Programa Institucional de Bolsas de Iniciação Científica Júnior PIBIC, com financiamento da Pró-Reitoria de Pesquisa da UFRGS. A partir do ano de 2003, quando ocorreu a criação do programa PIBIC Júnior (MASSI, QUEIROZ, 2015), a iniciação científica vem sendo reunida, a partir de elementos e escopos diversos, à educação básica. Nesse entendimento, o trabalho diz respeito ao conhecimento inicial que os orientadores da investigação na qual estão inseridos os bolsistas necessitam para reconhecer os elementos já construídos nos sujeitos sobre ciência e seus processos. Mais do que uma sondagem, tratou-se de instrumento de reconhecimento, de pensar sobre si, seus interesses e suas motivações. Os resultados da investigação associam-se, portanto, às aproximações e possibilidades daqueles que a constroem, tornando a pesquisa ao mesmo tempo uma ação de reflexão e uma forma de descoberta do novo.

Diversos autores têm debruçado seus esforços em ampliar a compreensão dos processos de iniciação científica na educação básica e, a partir de suas investigações, vêm constatando as potencialidades e os desafios enfrentados na busca por uma educação científica de qualidade (KRÜGER et al, 2013; BOCASANTA, KNIJNIK, 2016), da mesma forma que outros detém seus empenhos em pensar o desenvolvimento da criticidade e da autonomia dos estudantes da educação básica a partir de aproximações com a ciência (GEWEHR et al, 2016; SILVEIRA, CASSIANI, 2016). É oportuno, por sua vez, retomar o apontado por Mazzei (2013, p.47) quando intenciona afirmar que a "ciência e o conhecimento científico são pontos de vista em relação à abundância de opções que a natureza nos oferece" e, nesse sentido, encontra-se a iniciação científica presente no âmbito da escola, como aquela que "traz contribuições relevantes para a formação dos estudantes de nível médio" (DAMIELLI, 2018, p. 230).

Existem importantes desafios para a efetivação das práticas de ensino de iniciação científica na educação básica, e, dentre esses, se coloca a necessidade de que os docentes orientadores dessas investigações estejam em sintonia com o campo da pesquisa, uma vez que, segundo Lima (2017, p. 247), "o professor para planejar práticas pedagógicas inovadoras nesse macrocampo, precisa pensar cientificamente, ser crítico e criativo, bem como dispor de domínio de conhecimentos sobre a educação científica". Ainda, decorrente de múltiplos motivos, em especial as defasagens de proventos e a consequente necessidade de que os professores da educação básica da escola pública tenham que ampliar sua jornada semanal em até três turnos, a inserção no campo da pesquisa torna-se, em tantos casos, um plano cada dia mais afastado. Nesse sentido, Oliveira (2017), aponta que

orientar iniciação científica para estudantes do Ensino Médio requer formação pedagógica e epistemológica no que se refere às relações entre os sujeitos, às orientações como processo e às interferências da ciência no processo civilizatório" (OLIVEIRA, 2017, p. 271).

$\mathrm{E}$, para isso, a luta por condições dignas de trabalho também necessita ser alavancada a partir dessa leitura. Oliveira (2015, p. 254), por sua vez, ao tratar de investigação que estuda as bolsas de iniciação científica PIBIC-EM - voltadas para os estudantes do ensino médio - coloca que "os jovens bolsistas e suas famílias percebem o PIBIC-EM como uma porta de entrada no campo acadêmico, possibilitando o ingresso e a permanência na universidade e o acesso ao saber mais qualificado", ou seja, é possível pensar que para além das práticas e das vivências com iniciação científica no Ensino Médio, a possibilidade de que esses estudantes sejam bolsistas, potencializa ainda mais as condicionantes de acesso e permanência no ensino superior, por exemplo. Uma das possibilidades de inserção dos estudantes bolsistas de iniciação científica júnior no campo e no mundo da universidade trata-se da participação desses sujeitos em eventos científicos, como os salões de 
iniciação científica destinados para as escolas. Nesse sentido, Oliveira (2013), nos apresenta a reflexão sobre como a participação desses estudantes motiva-os a seguir na busca pelo conhecimento: "ao dizerem da participação em eventos acadêmicos nas mostras científicas, por exemplo, os estudantes demonstram se sentir competentes para aplicar socialmente os conhecimentos adquiridos sob novas formas" (p. 208). É inegável que, a partir desses processos de inserção, mesmo que inicial, no campo da pesquisa, "esses estudantes foram motivados pela curiosidade e possibilidade de ingressarem em um mundo onde a investigação oportuniza vivências, movimentando e construindo conhecimento" (COUTO, 2017, p. 107). Nesse sentido, o novo também instiga e desperta o desejo pela participação no campo da pesquisa, a partir da participação nos eventos acadêmicos e nos processos de construção das investigações em si.

\section{METODOLOGIA}

Tratou-se de uma investigação do tipo quantitativa-qualitativa, em relação à abordagem, visto que buscou analisar elementos numéricos e não-numéricos para possibilitar a compreensão das relações entre o tema da investigação e os sujeitos investigados da maneira mais completa possível. Quanto à natureza, tratou-se de investigação aplicada (GIL, 2007), uma vez que os conhecimentos construídos a partir da proposta investigativa podem ser aplicados nas realidades escolares nas quais já se realizam atividades relacionadas à iniciação científica ou, ainda, nas que pretendem realizar tais propostas, a partir do debate da percepção de ciência dos estudantes do Ensino Fundamental.

Quanto aos objetivos, a investigação pôde ser caracterizada como uma pesquisa descritiva, sendo que esses estudos são os que se caracterizam por descrever o comportamento dos fenômenos, buscando encontrar informações a respeito de uma determinada questão (COLLINS; HUSSEY, 2005), que, no caso em tela, tratou-se das percepções de ciência e iniciação científica de bolsistas de iniciação científica júnior, estudantes do Ensino Fundamental. E em relação aos procedimentos, tratou-se de pesquisa de levantamento de uma amostra já que, em consonância com Gil (2007), tais estudos se adequam aos estudos descritivos, uma vez que buscam analisar as opiniões acerca de determinados temas.

O espaço de realização deste estudo foi o Colégio de Aplicação da Universidade Federal do Rio Grande do Sul, escola pública federal, unidade acadêmica da UFRGS, localizada na zona leste da cidade de Porto Alegre, capital do RS. Essa instituição, quando da realização da investigação, atendia simultaneamente alunos do próprio bairro, bem como de bairros vizinhos e distantes e de outros municípios da Região Metropolitana de Porto Alegre e, a partir da conjunção com outros dados é composta por estudantes de diferentes perfis socioeconômicos e culturais. Os sujeitos da investigação foram os nove (9) bolsistas de iniciação científica júnior, do Programa de Bolsas de Iniciação Científica - PIBIC Educação Básica da UFRGS, selecionados no primeiro edital de 2020, todos dos anos finais do Ensino Fundamental e vinculados a um projeto de pesquisa relacionado ao tema da Iniciação Científica na escola básica, cuja descrição da amostra será apresentada no início dos resultados da investigação.

O instrumento de coleta de dados foi um questionário, dispositivo definido por Vieira (2009) e estruturado em três partes básicas. Na primeira, a caracterização da amostra de investigação, os participantes foram convidados a responder sobre sua idade, identificação de gênero, ano escolar, se possuíam acesso a computador e internet em suas residências e se já haviam participado de outros 
projetos de pesquisa, como bolsistas. Para a tabulação desses dados, os mesmos foram agrupados de modo a reconhecer as modas e maiorias destes.

Na segunda parte, denominada "escala Likert", os sujeitos foram provocados, a partir de três afirmações que apresentavam situações ou pensamentos relacionadas à ciência, e deveriam assinalar seu grau de concordância, indiferença ou discordância em relação à afirmação em tela. As afirmações adotadas para essa etapa do instrumento de coleta de dados foram: "a ciência é fundamental para o avanço da sociedade"; "o cientista trabalha em um laboratório" e "a ciência está relacionada unicamente com a disciplina de ciências". A escolha por essas afirmações se deu a partir da convenção dos pesquisadores, e, inclusive, a partir das leituras realizadas sobre o tema sondado. Para a tabulação desses dados, foram criados gráficos de barras, de modo a reconhecer tais graus já apontados. A escala Likert (1932) trata-se de metodologia de amplamente utilizada para pesquisa de opinião, nas mais diversas áreas, pela qual é possível verificar o grau de concordância plena ou parcial, indiferença ou discordância plena ou parcial em relação a determinado tópico. Tal técnica é descrita por pesquisadores como Osinski e Bruno (1998) e Trojan e Sipraki (2015), quando evidenciam as categorias de respostas e as perspectivas de estudos comparados com o uso da escala Likert.

A terceira parte do questionário apresentou três questões abertas para que os sujeitos da investigação pudessem dissertar, em um espaço curto, sobre o tema da proposta de pesquisa. As questões foram as seguintes: "Como os estudos científicos podem contribuir em situações como a pandemia que vivemos?"; "Quais são, na sua opinião, as atribuições de um bom cientista?" e "O que é ciência para você?". Desse modo, foi possível alargar as percepções de ciência dos estudantes, para além dos graus de concordância propostos na etapa anterior do instrumento de coleta de dados. Foi possível, portanto, reconhecer os múltiplos elementos que formam as argúcias dos bolsistas iniciantes em um novo projeto de pesquisa.

Em observância e atendimento às questões éticas na pesquisa (BRASIL, 2016), os participantes foram informados sobre os objetivos e o método da investigação, sobre o sigilo de seus dados e a possibilidade de deixarem de responder o questionário a qualquer momento, bem como os termos de consentimento livre e esclarecido foram assinados pelos pais ou responsáveis dos mesmos, haja visto o fato de que todos esses eram menores de idade, quando da coleta dos dados. Tal propositividade de garantias e respeito à ética na pesquisa também já haviam sido destacadas no projeto original da investigação e foram aprovadas tanto pela Comissão de Pesquisa da unidade acadêmica vinculada Colégio de Aplicação da UFRGS - quanto pelo Comitê de Ética na Pesquisa (CEP), tendo obtido parecer consubstanciado favorável.

Para fins de análise dos dados, as informações obtidas a partir do questionário foram discutidas de forma associada. O material foi submetido à análise de conteúdo (BARDIN, 1977) para que se descobrissem e analisassem as percepções dos diferentes sujeitos acerca de ciência, envolvendo o levantamento dos resultados a partir das afirmações dos sujeitos, foram interpretados e, a partir disso, foram construídas categorias de análise para cada uma das respostas. Os dados foram triangulados juntamente às leituras realizadas (referencial teórico), às informações sobre a amostra da pesquisa (pesquisa quantitativa), às respostas das afirmações apresentadas na escala Likert (pesquisa quantitativa) e às respostas das questões discursivas (pesquisa qualitativa). Essa triangulação de dados, segundo Minayo (2005), nesse tipo de pesquisa é fundamental para a compreensão de fenômenos e contribui para a validade da proposta investigativa. 


\section{RESULTADOS E DISCUSSÃO}

Os sujeitos deste estudo se identificaram, em sua maioria $(n=8)$, como do gênero feminino e em curso do 90 ano do Ensino Fundamental, sendo que somente um estudante frequentava naquele momento o $8^{\circ}$ ano daquela modalidade de ensino. Seis estudantes tinham 14 anos enquanto outros três tinham 15 anos no momento da aplicação do questionário. Tendo em vista as preocupações com os estudos em tempos de pandemia e buscando possibilitar o amplo acesso dos bolsistas ao processo de desenvolvimento de suas investigações e das atividades do grupo de pesquisa, verificou-se que todos os estudantes declararam possuir computador e internet em casa. No que se refere às experiências anteriores desses estudantes com a prática de fazer pesquisa, três deles afirmaram já terem sido bolsistas de programas de Iniciação Científica no ano anterior, em pesquisas de diferentes áreas do conhecimento: uma sobre doping e antidoping em jovens atletas, outra sobre narrativas de professores de Geografia, e outra, ainda, sobre iniciação e alfabetização científica.

Em relação à percepção de ciência dos estudantes, apresentam-se duas figuras que descrevem o grau de concordância dos alunos em relação a afirmações sobre ciência e sociedade, ciência e laboratório, e ciência e disciplina de ciências, a partir dos levantamentos realizados no modelo de escala Likert.

Em relação aos graus de concordância dos bolsistas frente à afirmação de que "a ciência é fundamental para o avanço da sociedade", foi possível verificar que a totalidade (100\%) dos alunos concordam "plenamente" com a essencialidade da ciência para o avanço da sociedade. Cabe ressaltar, primeiramente, que o reconhecimento de tal importância da ciência condiz com a realidade social, especialmente desde o advento da modernidade, que se caracteriza, entre outras associações, com o desenvolvimento do método científico e a separação sujeito-objeto. Por outro lado, parte dos estudos científicos tem questionado a ideia positivista de avanço e progresso da ciência e a partir dela, o que foi feito tanto por aqueles que propõem que a História é descontínua e não progressiva, como Hobsbawm (2012), quanto por aqueles que, conforme Chauí (2000), entendem que em cada época e para cada sociedade, aos conhecimentos e às práticas são atribuídos sentido e valor próprios, e que numa época seguinte estes desaparecem ou são diferentes, "não havendo, portanto, transformação contínua, acumulativa e progressiva" (p.60).

A Figura 1, em sequência, expõe os graus de concordância dos alunos com a afirmativa de que "o cientista trabalha em um laboratório".

Figura 1 - Graus de concordância com a afirmação: "O cientista trabalha em um laboratório".
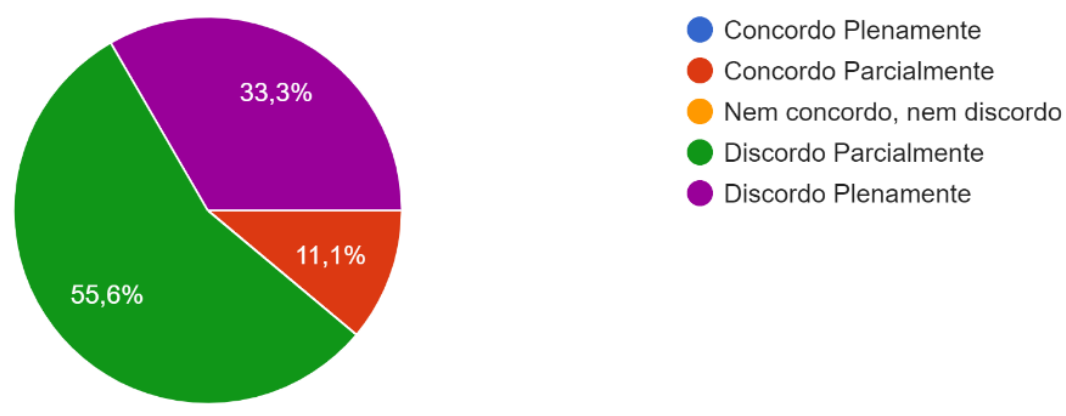

Organização: Os autores (2020).

A discordância em relação a esta afirmação se mostrou preponderante, com exceção de um sujeito que concordou em parte com a assertiva. Tal discordância era esperada, tendo em vista que a 
representação social de laboratório se alinha à lógica das ciências naturais. Estudos sobre a representação social do cientista têm se dedicado, segundo Brasil (2020), desde os anos 1950, a entender como tais atores sociais são percebidos por diferentes públicos. O cientista é percebido comumente por diferentes públicos, segundo Reznik et al (2017) portando jaleco e óculos, no laboratório, com fórmulas e jargões específicos, e normalmente a sua representação é de um homem branco de meia-idade. Nesse sentido, a diversidade de raça e gênero tem se mostrado de forma desigual nas representações do cientista.

Tal visão estereotipada do cientista, além de reproduzir e amplificar o preconceito, acaba por essencializar a ciência por um de seus espaços de ação, o laboratório. Estudos como o de Massarani et al (2019) têm mostrado que tal representação é formulada sobretudo pela mídia já que tudo o que conhecemos sobre a nossa sociedade, ou sobre o mundo em que vivemos, conhecemos através dos meios de comunicação de massa (LUHMANN, 2000). Nesse sentido, as representações sociais do cientista no laboratório podem ser mais bem analisadas se olharmos para a produção de sentidos exercida pelos meios de comunicação. O caráter público e social da linguagem, proposto por Hall (2016) na abordagem construtivista da linguagem, entende que as coisas não significam por si só, mas que tais significados são construídos em sistemas representacionais com conceitos e signos.

Por outro lado, ao direcionar o olhar para os meios de comunicação, há de se considerar que a abordagem intencional proposta por Hall (ibidem) deve ser considerada, em certa medida, ao analisar a mídia, já que, em acordo com a assertiva de Luhmann (ibidem), muitos sujeitos constroem suas representações de ciência somente a partir dos veículos de comunicação. Nesse sentido, os dados mostram que os estudantes observados, em sua maioria, já refutam tal indissociabilidade ciência-laboratório, mostrando certa autonomia frente às construções midiáticas, o que, inclusive, sugere a relevância do papel da escola que produz ciência como formadora de sujeitos autônomos e críticos.

A análise seguinte, indicada na Figura 2, foi feita com base nos graus de concordância dos alunos com o enunciado que afirma que "a ciência está relacionada unicamente com a disciplina de ciências".

Figura 2 - Graus de concordância com a afirmação: "A ciência está relacionada unicamente com a disciplina de ciências".

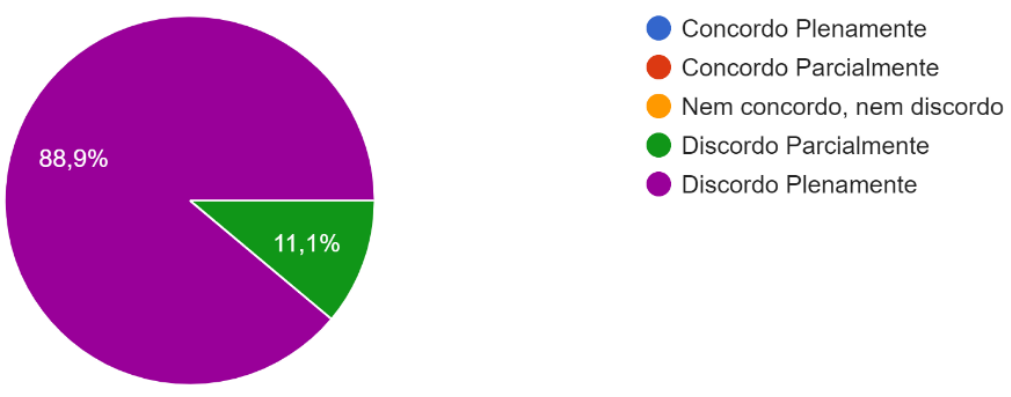

Organização: Os autores (2020).

A análise das respostas mostra que todos os sujeitos divergiram da vinculação de forma exclusiva entre os homônimos em questão, sendo que um deles afirmou discordar parcialmente, enquanto os demais discordaram plenamente. Nesse sentido, e de forma complementar ao distanciamento cientista-laboratório manifestado na análise anterior, verifica-se que os estudantes atenderam as expectativas de compreensão de que a produção científica não se restringe ao campo das ciências 
naturais, não está pautada tão somente na dualidade positivista de sujeito-objeto, e tampouco circunscreve-se à neutralidade do pesquisador frente à natureza.

Nesse sentido, os estudos que se dedicam a análises sociais da ciência, como os propostos por Latour (2019), auxiliam a compreender as relações entre sujeito e objeto defendidas pelo viés positivista. Para além de refutar tal paradigma consequencialista, Latour defende a coexistência de ciência e política, posto de outro modo, de natureza e cultura, na produção científica. Desse modo, crítica ao mesmo tempo o positivismo pela suposta neutralidade do sujeito e preponderância do objeto, bem como o relativismo pela predominância do sujeito e relativização do objeto. Nessa concepção, o trabalho de construção científica se caracteriza como um híbrido de ciência e política, sendo que o que ocorre de forma recorrente na divulgação das ciências naturais é um processo de purificação ao ocultar os interesses, associações, motivações na produção do fato. Tal reflexão aponta que o discernimento manifestado pelos estudantes demonstra que há concepções de ciência consideradas para além daquelas tradicionalmente associadas ao paradigma positivista e às Ciências da Natureza, o que, por sua vez, pode ser atribuído, entre outros espaços de significação, ao papel desempenhado pela escola e pela Iniciação Científica na educação básica.

Em seguida, encontra-se o quadro 1, o qual apresenta as categorias construídas a partir da análise das respostas discursivas dos estudantes frente à questão "Como os estudos científicos podem contribuir em situações como a pandemia que vivemos?". Foram realizadas duas análises para essa questão, tendo em vista a análise das "ações" (verbos) que os estudantes entendem que a ciência pode/deve fazer; bem como a análise do "conteúdo" manifestado nas respostas.

Quadro 1 - Análise de conteúdo das respostas sobre a relação entre os estudos científicos e a pandemia atual (Questão: Como os estudos científicos podem contribuir em situações como a pandemia que vivemos?)

\begin{tabular}{|c|c|c|c|}
\hline \multicolumn{2}{|r|}{ Ações } & \multicolumn{2}{|r|}{ Conteúdo } \\
\hline Categorias & Expressões verbais & Categorias & Termos empregados \\
\hline $\begin{array}{l}\text { 1) Tempo } \\
\text { presente }\end{array}$ & $\begin{array}{l}\text { espalha; morreram; acredito; } \\
\text { respeitar; possam ocorrer; } \\
\text { existisse; iremos passar; } \\
\text { podemos; manter bem; } \\
\text { estarmos vivos; termos nos } \\
\text { desenvolvido; estaríamos } \\
\text { vivendo; queima segue; } \\
\text { estamos; é transmitido; tem se } \\
\text { guiado; devem ocorrer; } \\
\text { sobrevivemos e chegamos; } \\
\text { estamos }(\text { sujeitos } \\
1,2,3,4,5,7,8)^{2}\end{array}$ & $\begin{array}{l}\text { A) Biológico, } \\
\text { sanitário }\end{array}$ & $\begin{array}{l}\text { Cura; vírus; contaminamento; } \\
\text { pandemia; vírus; vírus; vacina; } \\
\text { remédio; pandemia; máscaras; } \\
\text { higiene; vírus; Covid-19; cura; } \\
\text { coronavírus; infectadas; vírus; } \\
\text { pandemia; vírus; mortes; } \\
\text { vacina (sujeitos } 1,2,3,4,5,6,7 \text { ) }\end{array}$ \\
\hline $\begin{array}{l}\text { 2) Mudança, } \\
\text { transformação }\end{array}$ & $\begin{array}{l}\text { podemos evitar; criar; } \\
\text { queremos evitar; evitado; } \\
\text { eliminar; podemos mudar; } \\
\text { detê-lo; iremos; conseguir; } \\
\text { (sujeitos } 1,2,4,5,6,7,8 \text { ) }\end{array}$ & $\begin{array}{l}\text { B) Ciência, } \\
\text { científicos }\end{array}$ & $\begin{array}{l}\text { Descobrimento; estudos } \\
\text { científicos; importância; } \\
\text { estudos; informação; estudos } \\
\text { científicos; informações; } \\
\text { credibilidade; estudo; } \\
\text { científicos; desenvolvimento; } \\
\text { ciência; ciência; ciência; } \\
\text { pesquisas; estudos científicos; } \\
\text { observações; testes; estudos; } \\
\text { pesquisa; soluções; problema } \\
\text { (sujeitos } 1,2,3,4,7,8,9 \text { ) }\end{array}$ \\
\hline
\end{tabular}

2 Os números apresentados no quadro dizem respeito aos sujeitos da pesquisa que apresentaram expressões relativas às categorias discutidas. 


\begin{tabular}{|l|l|l|l|}
\hline & $\begin{array}{l}\text { Conhecermos; conhecer; } \\
\text { tomem consciência; podemos } \\
\text { tentar; entender o que é; } \\
\text { perceber; temos a capacidade } \\
\text { de perceber; buscando saber; } \\
\text { evitá-lo; conseguimos saber; } \\
\text { entendimentonento } \\
\text { funcionam; podem trazer; } \\
\text { (sujeitos 2,3,6,7,8,9) }\end{array}$ & $\begin{array}{l}\text { C) } \\
\text { Comportamento, } \\
\text { hábito }\end{array}$ & $\begin{array}{l}\text { Atitudes; isolamento social; } \\
\text { prevenção; mentalmente; } \\
\text { pessoas; política; reação; } \\
\text { sociedade; isolamento; } \\
\text { isolamento social (sujeitos } \\
3,4,5,6,7)\end{array}$ \\
\hline $\begin{array}{l}\text { Contribuição, } \\
\text { ajuda }\end{array}$ & $\begin{array}{l}\text { Contribuir; contribuíram; } \\
\text { poderão contribuir; podem } \\
\text { contribuir; podemos ajudar; } \\
\text { ajudando; possa ajudar; } \\
\text { ajudou (sujeitos 1,2,4,5,7) }\end{array}$ & $\begin{array}{l}\text { D) Relação sujeito- } \\
\text { tempo-mundo }\end{array}$ & $\begin{array}{l}\text { Mortes; mortes; saúde; vida; } \\
\text { humanidade; da pedra; tempo; } \\
\text { recorde; mundo (sujeitos } \\
2,4,7,8)\end{array}$ \\
\hline
\end{tabular}

Organização: Os autores (2020).

A percepção dos alunos sobre as ações dos estudos científicos frente à pandemia resultou em quatro categorias: 1) "Tempo presente", com 20 ocorrências em oito respostas; 2) "Mudança, transformação", com 11 ocorrências em sete respostas; 3) "Conhecimento, entendimento", em 11 ocorrências em seis respostas; e 4) "Contribuição, ajuda", a qual teve oito ocorrências em cinco respostas. Todas as categorias têm relação com o que se espera da ciência e, nesse sentido, as respostas dos estudantes demonstram a amplitude de ações que a ciência deve ter, tanto para a compreensão do presente (categorias 1 e 3 ) quando para as perspectivas de futuro (categorias 2 e 4). Por outro lado, o entendimento do passado não foi uma preocupação para os alunos, o que chama a atenção, dado que o entendimento sobre a origem do vírus ou, então, sobre pandemias em outros tempos históricos, por exemplo, é fundamental para a compreensão do presente e para a previsão de ações.

Nesse sentido, alguns estudiosos (LATOUR, 2020; VASQUES; OLIVEIRA, 2020) têm afirmado que a ciência nunca esteve tão presente na vida da sociedade, sendo que nesse período a ciência, os estudos, cientistas, vacinas, instituições se transformaram em assunto repercutido por muitos atores, como youtubers, programas de TV, jornalistas, dirigentes esportivos, etc. Tal profusão da ciência nos tempos de pandemia, apesar de preocupantemente mobilizar movimentos negacionistas, ortodoxos e antissistêmicos, parece ter feito com que a ciência ocupe o dia-a-dia de pessoas que não tinham costume de falar sobre esse assunto. Apesar de esses sujeitos, e mesmo alguns que deveriam estar mais bem informados, ainda não terem clareza de que a ciência não oferece respostas definitivas, como afirma Latour (2020) em recente entrevista, esse movimento de propagação da ciência pode ser benéfico ao considerar que o público aprendeu muito sobre a ciência para além do seu papel de informação e da transmissão de conhecimento, podendo observar as disputas, as vantagens, desvantagens, fragilidades e forças, o que, segundo o pesquisador, foi muito útil exatamente por mostrar a hibridez da produção científica.

As categorias construídas a partir da análise de conteúdo mostram essa apropriação dos estudantes, ao elencarem de forma usual termos do campo científico que vêm sendo empregados atualmente, como "vírus", "pandemia", "vacina", "remédio", "infectadas", e chama mais ainda a atenção a hibridez das análises desses jovens ao elencarem ao lado expressões que costumamos chamar de políticas, mas que são parte, como dito, da produção científica: "credibilidade", "atitudes", "prevenção", "política", "reação", "sociedade". A visualização da hibridez do campo científico, no sentido apontado por Latour (2019), reitera a compreensão ampla de ciência desses estudantes, bem como ratifica a propalação da ciência na sociedade a partir da pandemia. 
As quatro categorias de análise de conteúdo construídas a partir das respostas sobre a relação da ciência com a pandemia foram: A) "Biológico, sanitário" com 21 citações em sete respostas; B) "Ciência, científicos", também com 21 citações em sete respostas; C) "Comportamento, hábito" que apresentou nove citações em cinco respostas; e D) "Relação sujeito-tempo-mundo" com sete referências em cinco respostas. A análise dessas categorias indica (categoria A) a apropriação de termos do campo das ciências biológicas e epidemiológicas, bem como a preocupação com a relação desses fatores com a comportamentos e interesses dos sujeitos (categoria C). $\mathrm{O}$ aparecimento da categoria B sugere que os alunos reconhecem certas funções sociais da ciência (termos "soluções", "problemas", "credibilidade"), bem como certos instrumentos que vem sendo utilizados pelas pesquisas nesse contexto ("observações", "testes").

Por fim, a categoria $D$ indica que a preocupação com a vida e com o tempo no mundo deve ser função da ciência nesse período. Tal noção, frequente nas ciências da saúde e recorrente na mídia em tempos de pandemia, contrasta com certa visão de uso da ciência para o progresso econômico e tecnológico, debate que, inclusive, tomou conta da mídia durante esse período. Tal consideração se trata de um falso dilema, como afirmam Schramm et al (2020), tendo em vista que o isolamento das populações deve "ser visto, sobretudo, como um ato de responsabilidade" (p.2), posição que foi reforçada pela Organização Mundial da Saúde (OMS) e até mesmo pelo Fundo Monetário Internacional (FMI). Tais preocupações dos estudantes foram certamente construídas nas suas relações sociais, as quais se aproximaram dos sujeitos com quem eles coabitam nesse período de isolamento. Ainda assim, pode-se ver que tal leitura da realidade tem relação direta com alguns consensos científicos contemporâneos, no caso, aqueles preocupados com a vida, a saúde e os comportamentos sociais.

Em sequência, realizou-se uma análise de conteúdo a partir das respostas dos estudantes à questão: "Quais são, na sua opinião, as atribuições de um bom cientista?", a qual está apresentada no quadro 2.

Quadro 2 - Análise de conteúdo das atribuições de um "bom cientista" (Questão: "Quais são, na sua opinião, as atribuições de um bom cientista?").

\begin{tabular}{|c|c|}
\hline Categoria & Expressões utilizadas \\
\hline $\begin{array}{l}\text { a) Disposição/interesse } \\
\text { em saber }\end{array}$ & $\begin{array}{c}\text { disposto a sempre aprender; interesse em saber novos assuntos; ser focado; } \\
\text { um questionamento; observar; curioso; dedicado; Curiosidade; interesse; sem } \\
\text { ter medo de errar (Sujeitos } 2,3,4,7,9 \text { ) }\end{array}$ \\
\hline $\begin{array}{l}\text { b) Questionamento e } \\
\text { relativização }\end{array}$ & $\begin{array}{c}\text { nunca tomar uma verdade como absoluta; aberto a novas alternativas; mais } \\
\text { dúvidas ter a mente aberta para ver as coisas sob múltiplas perspectivas; } \\
\text { estar com a mente aberta }(2,3,6,7,8)\end{array}$ \\
\hline $\begin{array}{l}\text { c) Produção de } \\
\text { conhecimento }\end{array}$ & $\begin{array}{l}\text { realiza uma pesquisa; produz conhecimento; desenvolvimento de novos } \\
\text { assuntos; buscar uma solução; Conhecimento; criatividade }(1,4,6,9)\end{array}$ \\
\hline d) Sujeito-sociedade & $\begin{array}{l}\text { mudando a forma de pensar das pessoas; bom relacionamento; mostram } \\
\text { realidades de pessoas que não são vistas ou ouvidas }(1,3,5)\end{array}$ \\
\hline e) Ética & $\begin{array}{c}\text { saber errar e corrigir o erro; não deixar sua vida pessoal interferir na } \\
\text { profissional }(2,8)\end{array}$ \\
\hline
\end{tabular}

Organização: Os autores (2020).

A análise das percepções dos estudantes sobre as atribuições de um "bom cientista" permitiu a construção de cinco categorias analíticas. A categoria "disposição/interesse em saber" ("a") foi citada dez vezes por cinco respondentes, e, em sequência, também citada por cinco sujeitos, aparece a categoria "questionamento e relativização" ("b"), a qual teve quatro citações. Quatro respostas, em seis expressões, consideraram a "produção de conhecimento" ("c") como uma 
atribuição importante, enquanto três sujeitos (em três citações) indicaram que a relação "sujeitosociedade" ("d") é fundamental. Ainda, a dimensão "ética" ("e") apareceu em duas respostas.

Todas as indicações consideradas pelos estudantes fazem sentido ao pensar o cientista/pesquisador ${ }^{3}$ como um sujeito que tem interesse em saber, que questiona e que produz conhecimento. Ainda, destaca-se a preocupação de dois estudantes com a dimensão ética da pesquisa, central no processo de produção do conhecimento, ainda mais ao refletir sobre as necessidades do produtivismo acadêmico, engajamento no qual todos nós nos sentimos coagidos a participar, e cuja preocupação reside, em acordo com Vilaça e Palma (2015), no distanciamento da noção de quantidade da qualidade da produção científica.

Nesse sentido, há de se compreender que as atribuições de um "bom cientista" não são definidas somente pelo seu caráter ou pela sua disposição, mas por disposições que são construídas em conjunto com as estruturas sociais disponíveis, o que faz com que olhar para a ética na pesquisa exija observar as lógicas internas e os troféus que estão em disputa no campo científico. Tal observação, em acordo com as propostas por Bourdieu (1975), possibilitam entender que os capitais individuais que são considerados importantes e distintivos no campo científico e obtidos pelas contribuições à ciência, mas também pelas estratégias políticas e institucionais. Desse modo, não há como entender os atributos necessários a um pesquisador sem entender as regras de funcionamento do campo científico.

Desse modo, chama a atenção que a percepção dos estudantes sobre o cientista estivesse, em colisão à noção estrutural de campo, quase que totalmente associada a atributos individuais, exceto pela categoria "d", configurada em expressões citadas por três sujeitos as quais consideraram como atributo do cientista uma dimensão relacional/social. Nesse ínterim de interesse das ciências sociais, Bourdieu (1998) vai entender a divisão indivíduo-sociedade como artificial, tipicamente escolástica, cujos interesses propõem destruir o estado de bem-estar social bem como a noção de responsabilidade coletiva. Tais processos de naturalização dos atributos e processos sociais como resultados de ações individuais, como o gosto e o talento, por exemplo, são muitas vezes produzidos e reproduzidos pela própria escola em consequência das próprias transformações na estrutura do campo escolar. Nessa perspectiva, e tendo em vista o caráter individual dos atributos percebidos pelos estudantes em relação aos cientistas, faz-se necessário refletir no ambiente escolar sobre o caráter coletivo dos processos de incorporação e manifestação de opiniões, valores e ideias.

O quadro 3, apresentado a seguir, indica as categorias construídas com base no conteúdo das respostas dos estudantes à pergunta: "O que é ciência para você?".

\footnotetext{
${ }^{3}$ A reflexão sobre gênero é parte importante dos estudos sobre percepção e representação dos cientistas, já que tais representações ainda permanecem associadas ao cientista homem (e branco). Nesse entendimento, cabe ressaltar a importância de tal desvinculação na escola, espaço privilegiado para desconstruir tais estereótipos formulados e reforçados pelo senso comum e, em especial, pela mídia. Com base nessa lógica, faz-se necessário explicar que seguiremos o padrão normativo da língua portuguesa, que concede privilégio de gênero e, com isso, reforça estereótipos.
} 
Quadro 3 - Análise de conteúdo da percepção sobre o conceito de ciência (Questão: "O que é ciência para você?").

\begin{tabular}{|c|c|}
\hline Categoria & Expressões utilizadas \\
\hline $\begin{array}{l}\text { I. Ferramenta, } \\
\text { instrumento }\end{array}$ & $\begin{array}{l}\text { método; utilizamos a ciência; pesquisa; forma; método; pesquisa; forma de } \\
\text { conhecimento; construção do conhecimento }(1,2,3,4,5,6,7,9)\end{array}$ \\
\hline $\begin{array}{l}\text { II. Aprendizado, } \\
\text { conhecimento }\end{array}$ & $\begin{array}{l}\text { adquirir conhecimento; aprender; conhecer; descobrir; adquire um conhecimento } \\
\text { mais profundo; objetivos; descobrimos inúmeras coisas; aprendermos as coisas; } \\
\text { desconhecido ou sobre algo conhecido; entendido; explicar ou responder } \\
\text { questões; adquiríamos conhecimentos; conhecimentos; resultados }(1,2,3,4,5,6,8)\end{array}$ \\
\hline $\begin{array}{l}\text { III. Estudo, } \\
\text { pesquisa }\end{array}$ & $\begin{array}{l}\text { estudo de determinada coisa; estudar; pesquisa; pesquisas; observação; } \\
\text { pesquisa; observações; estudos; pesquisa; investigação }(2,3,4,7,8,9)\end{array}$ \\
\hline IV. Amplitude & $\begin{array}{c}\text { está praticamente em tudo; variadas formas; evoluir; quaisquer assuntos } \\
\text { possíveis sanar qualquer tipo de dúvida; ampla }(2,3,6,7,8)\end{array}$ \\
\hline $\begin{array}{l}\text { V. Escolha do } \\
\text { tema/área }\end{array}$ & $\begin{array}{l}\text { goste; experiências; áreas do conhecimento; assunto; vida humana; tema } \\
\qquad(1,3,4,9)\end{array}$ \\
\hline $\begin{array}{l}\text { VI. Tipos de } \\
\text { saberes }\end{array}$ & $\begin{array}{c}\text { ciência não dá conta de responder tudo; conhecimentos ancestrais; a ciência não } \\
\text { tem como provar ou refutar (7) }\end{array}$ \\
\hline
\end{tabular}

Organização: Os autores (2020).

A observação da percepção do conceito de ciência dos estudantes resultou na construção de seis categorias empírico-analíticas: I. "Ferramenta, instrumento", em oito respostas; II. "Aprendizado, conhecimento", apresentada em sete retornos; III. "Estudo, pesquisa", a qual foi descrita por seis estudantes; IV. "Amplitude", manifestada por cinco respostas; V. "Escolha do tema/área", manifestada por quatro respondentes; e VI. "Tipos de saberes", a qual apareceu em uma resposta. De modo geral, é possível afirmar que os estudantes percebem a ciência de forma ampla (IV), relacionando-a com a necessidade de estudo (III), sendo, desse modo, uma ferramenta, um instrumento (I), para a construção do conhecimento (II). Ainda, os estudantes chamam a atenção para a escolha do tema/área ( $\mathrm{V}$ ) de estudo a partir do gosto, concepção discutida anteriormente que incorre na separação indivíduo-sociedade.

Cabe destacar, por sua vez, a manifestação em uma resposta de que existem "tipos de saberes". Tal compreensão vem de encontro aos estudiosos da filosofia da ciência, os quais entendem que a ciência é uma forma moderna e racional de sistematização, ordenação, disciplinamento do conhecimento. Nessa discussão, apesar de muitos entenderem que a ciência moderna se instituiu contra o senso comum porque o considerava falso, tal posição, conforme Santos (1989), não é compartilhada pelas ciências humanas, já que algumas como a fenomenologia não romperam com o senso comum, bem como outras não são unânimes e, por vezes, destacam questões positivas e negativas do senso comum. Para o autor, se faz necessária uma dupla ruptura epistemológica, a qual exige um trabalho de transformação desses dois saberes, tornando o senso comum esclarecido e a ciência prudente.

Tal posição, em certa medida relativista e pragmática, se alia à noção de ciência como o "mito do porto seguro", a qual foi desenvolvida por Demo (1995). Tal proposição de entendimento da ciência refuta o caráter autoritário de verdades estabelecidas e de autoridade inquestionável da ciência. Em contraponto, fazem parte do processo de produção da ciência o erro, a incerteza e a crítica, bem como a provisoriedade das verdades. Tais entendimentos em nada permitem subvalorar a relevância social da produção científica como critério de verdade, ao contrário, é também pelo seu próprio caráter provisório e questionador de si que a ciência se torna o método mais confiável para conhecer. A compreensão dessas desestabilidades, incertezas e críticas deve ser parte da formação 
científica dos estudantes, os quais ainda percebem a ciência de forma mais ou menos homogênea, estável e detentora da verdade.

\section{CONSIDERAÇÕES FINAIS}

Neste trabalho foi possível construir um panorama das percepções e representações de estudantes bolsistas de iniciação científica júnior sobre ciência. O principal objetivo do trabalho foi analisar as percepções e representações de ciência e iniciação científica na escola de bolsistas de iniciação científica júnior, estudantes do Ensino Fundamental do Colégio de Aplicação da UFRGS, vinculados ao Programa Institucional de Bolsas de Iniciação Científica Júnior PIBIC. Para atingir este objetivo, aplicou-se um questionário dividido em três partes principais, a caracterização da amostra da investigação, a verificação dos graus de concordância, indiferença ou discordância em relação a três afirmações que apresentavam situações ou pensamentos relacionados à ciência e as respostas a três perguntas abertas sobre o tema da ciência, mais voltadas ao cotidiano dos bolsistas, as quais possibilitaram atingir aos objetivos específicos da investigação.

As leituras teóricas realizadas indicaram o entendimento de que a iniciação científica no âmbito da escola básica apresenta significativas intencionalidades, na medida em que possibilita a construção de conhecimentos científicos desde a escola e, ainda, o desenvolvimento do processo de trabalho com o método científico com estudantes do Ensino Fundamental e médio. Ainda, fazem lembrar a importância que os Programas Institucionais de Bolsas de Iniciação Científica Júnior adquirem nos contextos escolares, uma vez que o fomento à pesquisa, desde as bases, antes mesmo da clássica iniciação científica da graduação, alavanca o interesse pela pesquisa e possibilita vislumbres de futuro, inclusive para as camadas menos abastadas da sociedade.

Ao caracterizar a amostra da investigação foi possível conhecer, ainda que em apenas cinco tópicos (idade, gênero, idade, ano escolar, acesso à computador e internet e participação em outros projetos de pesquisa, como bolsistas), os sujeitos da pesquisa, a partir das informações coletadas. A caracterização da amostra de uma pesquisa permite aos pesquisadores um reconhecimento inicial do campo e dos sujeitos, de maneira a identificar as possíveis futuras relações com os demais espaços do instrumento de coleta de dados, o questionário, como adotado no caso em questão. Em relação à idade, a maior parte dos sujeitos estudantes era composta por participantes com 14 anos. Em relação ao gênero, os bolsistas, em massiva maioria, identificam-se com o gênero feminino. Sobre o ano escolar em curso, a maioria também se encontrava no $9^{\circ}$ e último ano do Ensino Fundamental. Todos os sujeitos da investigação possuíam computador com acesso à internet em casa, dado importante, em meio aos estudos remotos ocasionados em decorrência da pandemia da COVID-19. A maioria, igualmente, não havia participado de pesquisa como bolsista, sendo sua primeira experiência nessa modalidade.

Ao apresentar três frases relacionadas à temática da ciência aos sujeitos da investigação e solicitar que manifestassem seu grau de concordância, indiferença ou discordância, interessantes análises puderam ser feitas: na afirmação "a ciência é fundamental para o avanço da sociedade", na qual percebeu-se que a totalidade dos sujeitos possuía grau de concordância plena com a mesma, denotando não apenas o reconhecimento da ciência enquanto instituição necessária, mas, ao mesmo tempo, depositando confiança em sua ação. Na afirmação "o cientista trabalha em um laboratório", foi possível verificar que a maioria encontrava-se nos graus de discordância (plena ou parcial) em relação a mesma, evidenciando a não necessária relação sujeito-objeto largamente construída ao 
longo do tempo, pelo senso comum. Por fim, a afirmação "a ciência está relacionada unicamente com a disciplina de ciências" teve, como totalidade, sujeitos nos graus de discordância, o que aponta igualmente para a amplitude de percepções nas quais a ciência pode estar envolvida, para além das clássicas, relacionadas às ciências naturais.

A partir da análise de conteúdo desenvolvida com as respostas obtidas nas três perguntas abertas realizadas, foi possível verificar novos olhares sobre ciência dos sujeitos da investigação. A questão "Como os estudos científicos podem contribuir em situações como a pandemia que vivemos?" trouxe à tona análises de respostas em um olhar voltado às ações (no tempo presente, na mudança/transformação, no conhecimento/entendimento e nas contribuição/ajuda) e aos conteúdos (biológico/sanitário, ciência/científico, comportamento/hábito e relação sujeito-tempomundo) relacionados à ciência como um todo. Na questão "Quais são, na sua opinião, as atribuições de um bom cientista?" foi possível verificar e localizar cinco categorias emergentes de análise, do que seriam tais "atribuições" do "bom cientista". São elas: disposição/interesse em saber; questionamento e relativização; produção de conhecimento; sujeito-sociedade e ética. Tais concepções demonstram o conhecimento inicial sobre o que se denominaria da "profissão cientista" e, ainda, os desejos relacionados às expectativas de resultados dos profissionais do campo. Por fim, a questão "O que é ciência para você?" trouxe à discussão seis importantes categorias de reconhecimento dos sujeitos da pesquisa, em relação ao objeto do estudo, ao entenderem a ciência como: ferramenta/instrumento; aprendizado/conhecimento; estudo/pesquisa; amplitude; escolha do tema/área ou tipos de saberes, o que demonstra a compreensão da ciência, dentre os múltiplos aspectos que podem ser considerados, como algo em constante processo de busca pelo conhecimento que favoreça o bem comum.

A visualização de tais resultados possibilitou o atravessamento de discussões caras ao campo dos estudos sociais da ciência. Desse modo, os dados empíricos trouxeram à tona os debates sobre: a crítica à ideia positivista de avanço e progresso da e a partir da ciência; a representação social da ciência e do cientista, e a importância dos meios de comunicação de massa; a hibridez de ciência e política para a produção do fato científico; o produtivismo científico e o distanciamento entre a quantidade e a qualidade; a noção de campo científico e o binômio indivíduo-sociedade; o senso comum e o mito do porto seguro da ciência; e a propagação e popularização da ciência nos tempos de pandemia e crise. Tais reflexões, ao mesmo tempo que permitem refletir sobre as percepções e representações sociais da ciência dos estudantes, podem ser utilizadas como forma de aproximar esses conhecimentos já produzidos pelo campo científico dos estudantes em formação escolar em iniciação científica júnior.

Conhecer as percepções sobre ciência de estudantes bolsistas de iniciação científica júnior, não se configura, então, como algo importante apenas à realidade escolar estudada, mas sim para todo e qualquer professor, outras realidades educativas do Brasil e outros projetos de pesquisa que busquem trabalhar com o tema da ciência na escola, já que as bagagens trazidas pelos estudantes devem sempre ser utilizadas como referência para partir das bases de conhecimentos já existentes nos alunos e, com isso, possibilitar a exploração de novos horizontes, o que poderia ser entendido como um pequeno milagre moderno que a educação como um todo vem realizando com empenho, esmero e dedicação possíveis. 


\section{REFERÊNCIAS}

BARDIN, Laurance. Análise de conteúdo. Lisboa: Edições 70, 1977.

BOCASANTA, D. M.; KNIJNIK, G. Dispositivo de tecnocientificidade e iniciação científica na educação básica. Currículo sem Fronteiras 16(1), 139-158, 2016. Disponível em:

https://www.curriculosemfronteiras.org/vol16iss1articles/bocasanta-knijnik.pdf Acesso em: 04 set. 2020.

BOURDIEU, Pierre. La spécificité du champ scientifique et les conditions sociales du progrès de la raison. Sociologie et societés. v.7, n.1, p.91-118, 1975.

BOURDIEU, Pierre.Contrafogos: táticas para enfrentar a invasão neoliberal. Rio de Janeiro: Jorge Zahar Ed., 1998.

BRASIL. Ministério da Saúde. Conselho Nacional de Saúde. Resolução 510, de 07 de abril de 2016. Dispõe sobre as normas aplicáveis a pesquisas em Ciências Humanas e Sociais. Disponível em: http://bvsms.saude.gov.br/bvs/saudelegis/cns/2016/res0510_07_04_2016.html Acesso em: 04 set. 2020.

BRASIL, Karine Brandão Nunes. "Desenhe um cientista": as concepções dos estudantes do Centro Juvenil de Ciência e Cultura sobre os cientistas. Revista Cenas Educacionais. v.3, n.e8670, p.1-15, 2020. Disponível em:

https://www.revistas.uneb.br/index.php/cenaseducacionais/article/view/8670 Acesso em: 04 set. 2020.

CHAUÍ, Marilena. Convite à filosofia. São Paulo: Ática, 2000.

COLLINS, J.; HUSSEY, R. Pesquisa em Administração: um guia prático para alunos da graduação e pós-graduação. Porto Alegre: Bookman, 2005.

COUTO, M. R. A. M. Os Clubes de Ciências e a Iniciação à Ciência: uma Proposta de Organização no Ensino Médio. 2017. Dissertação (Mestrado Profissional em Ensino de Ciências) - Programa de Pós-Graduação em Ensino de Ciências, Universidade de Brasília, Brasília, 2017.

DAMINELLI, E. A pesquisa e a produção de conhecimento nos Institutos Federais de Educação, Ciência e Tecnologia no RS: um estudo sobre a iniciação científica com estudantes do ensino médio técnico. 2018. Tese (Doutorado em Educação) - Programa de Pós-Graduação em Educação, Universidade Federal do Rio Grande do Sul, Porto Alegre, 2018.

DEMO, Pedro. Metodologia científica em ciências sociais. São Paulo: Atlas, 1995.

GEWEHR, D. et al. Metodologias ativas de ensino e de aprendizagem: uma abordagem de iniciação à pesquisa. Revista Ensino \& Pesquisa 14(1), 225-246, 2016. Disponível em:

http://periodicos.unespar.edu.br/index.php/ensinoepesquisa/article/view/843 Acesso em: 04 set. 2020.

GIL, Antônio Carlos. Métodos e técnicas de pesquisa social. São Paulo: Atlas, 2007.

HALL, Stuart. Cultura e representação. Rio de Janeiro: Editora PUC-Rio: Apicuri, 2016.

HOBSBAWM, Eric. A produção em massa das tradições: Europa, 1870 a 1914. In: HOBSBAWM, Eric; RANGER, Terence (org.). A invenção das tradições. Rio de Janeiro: Nova Fronteira, 2012, p. 327-379. 
KRÜGER, J. G. et al. Alfabetização científica com enfoque CTSA: produção de um jornal da ciência no Ensino Médio público. Revista Eletrônica Debates em Educação Científica e Tecnológica 3(2), 79-97, 2013. Disponível em: http://oasisbr.ibict.br/vufind/Record/IFES1_1518fb2042eb1b7cdf385893138bdfce Acesso em: 04 set. 2020.

LATOUR, Bruno. Jamais fomos modernos: ensaio de antropologia simétrica. São Paulo: Editora 34, 2019.

LATOUR, Bruno. Entrevista com Bruno Latour. Alyne Costa e Tatiana Roque. 2020. Disponível em: https://n-1edicoes.org/132 Acesso em: 14 ago. 2020.

LATOUR, B. Ciência em ação: como seguir cientistas e engenheiros sociedade afora. São Paulo: UNESP, 2000.

LIKERT, Rensis. A Technique for the Measurement of Attitudes, Archives of Psychology, 140: 155, 1932.

LIMA, Sônia Maria Pereira de. Inovação pedagógica, práticas pedagógicas inovadoras e concepções docentes no macrocampo iniciação científica e pesquisa do PROEMI. 2017. 271 f. Dissertação (Mestrado em Educação) - Programa de Pós-Graduação em Educação, Universidade Federal do Rio Grande do Norte, Natal, 2017.

LUHMANN, Niklas. The reality of the mass media. Cambridge: Polity Press, 2000.

MASSARANI, Luisa; CASTELFRANCHI, Yurij; PEDREIRA, Anna Elisa. Cientistas na TV: como homens e mulheres da ciência são representados no Jornal Nacional e no Fantástico. Cadernos Pagu. v.56, n.e195615 p.1-34, 2019. Disponível em:

https://www.scielo.br/scielo.php?script=sci_arttext\&pid=S0104-83332019000200505 Acesso em: 04 set. 2020.

MASSI, Luciana; QUEIROZ, Salete L. (orgs). Iniciação científica: aspectos históricos, organizacionais e formativos da atividade no ensino superior brasileiro. São Paulo: Editora UNESP, 2015.

MAZZEI, L.D. Iniciação científica na escola: uma abordagem pluralista. Cadernos do Aplicação. V.26, n.2, p.39-47, 2013. Disponível em: https://seer.ufrgs.br/CadernosdoAplicacao/article/view/43140 Acesso em: 04 set. 2020.

MINAYO, Maria Cecília de Souza. Conceito de avaliação por triangulação de métodos. Em: M. C, Minayo, S. G, Assis, \& E. R, Souza (Eds), Avaliação por triangulação de métodos. Abordagem de programas sociais (pp. 19-51). Rio de Janeiro: Fiocruz, 2005.

OLIVEIRA, Gisele Brandão Machado de. Percursos dos jovens de escolas públicas de ensino médio e Profissional no Programa de iniciação científica júnior da UFMG. 2013. 272 f. Tese (Doutorado em Educação, Conhecimento e Inclusão Social) - Programa de Pós-Graduação em Educação, Conhecimento e Inclusão Social, Universidade Federal de Minas Gerais, Belo Horizonte, 2013.

OLIVEIRA, A. A iniciação científica júnior (ICJ): aproximações da educação superior com a educação básica. 2015. Tese (Doutorado em Educação) - Programa de Pós-Graduação em Educação, Universidade Federal de Santa Catariana, Florianópolis, 2015. estudantes do ensino médio. 2017. 343 f. Tese (Doutorado em Educação Científica Tecnológica) 
- Programa de Pós-Graduação em Educação Científica Tecnológica, Universidade Federal de Santa Catariana, Florianópolis, 2017.

OSINSKI, Isabel Cañadas; BRUNO, Alfonso Sánchez. Categorías de respuesta en escalas tipo Likert. Psicothema, 1998. vol. 10, no 3, pp. 623-631. Disponível em: http://www.psicothema.es/pdf/191.pdf Acesso em: 04 set. 2020.

REZNIK, Gabriela; MASSARANI, Luisa Medeiros; RAMALHO, Marina et al. Como adolescentes apreendem a ciência e a profissão de cientista? Estudos Feministas. v. 25, n. 2, p.829-855, 2017. Disponível em: https://www.scielo.br/scielo.php?pid=S0104-

026X2017000200829\&script=sci_abstract\&tIng=pt Acesso em: 04 set. 2020.

SANTOS, Boaventura de Sousa. Introdução a uma ciência pós-moderna. Rio de Janeiro: Graal, 1989.

SCHRAMM, Fermin Roland; BORGES, Luna; FORTES, Pablo et al. 0 aparente dilema implicado pela pandemia da COVID-19: salvar vidas ou a economia? Observatório Covid-19 Fiocruz, 2020.Disponível em: https://www.arca.fiocruz.br/handle/icict/41374 Acesso em: 14 ago. 2020.

SILVEIRA, José Carlos da; CASSIANI, Suzani. Iniciação científica no Ensino Fundamental: a escola e seu lugar problematizador das relações entre ciência, tecnologia e sociedade. Sensos-e 3(2), 2016. Disponível em: http://sensos-e.ese.ipp.pt/?p=11715 Acesso em: 04 set. 2020.

TROJAN, Rose Meri; SIPRAKI, Robson. Perspectivas de estudos comparados a partir da aplicação da escala Likert de 4 pontos. Revista Ibero-Americana de Estudos em Educação, vol. 10, n. 2, 2015, págs. 275-300. Disponível em: https://periodicos.fclar.unesp.br/iberoamericana/article/view/7761 Acesso em: 04 set. 2020.

VASQUES, Daniel Giordani; OLIVEIRA, Victor Hugo Nedel. A iniciação científica na educação básica e a indissociabilidade ciência-escola. Jornal da Universidade. UFRGS. Porto Alegre, 2020. Disponível em: https://www.ufrgs.br/jornal/a-iniciacao-cientifica-na-educacao-basica-e-aindissociabilidade-ciencia-escola/ . Acesso em: 24 jul. 2020.

VIEIRA, Sonia. Como elaborar questionários. São Paulo: Atlas, 2009.

VILAÇA, Murilo Mariano; PALMA, Alexandre. Comentários sobre avaliação, pressão por publicação, produtivismo acadêmico e ética científica. Cadernos de Pesquisa. V.45, n.158, 2015. Disponível em: https://www.scielo.br/pdf/cp/v45n158/1980-5314-cp-45-158-00794.pdf Acesso em: 19 ago. 2020.

Submissão: 18/09/2020

Aceito: 07/10/2020 